Jurnal Keperawatan Silampari

Volume 4, Nomor 1, Desember 2020

e-ISSN: 2581-1975

p-ISSN: 2597-7482

DOI: https://doi.org/10.31539/jks.v4i1.1328

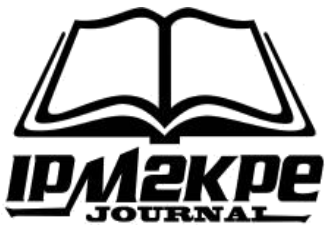

\title{
PERAWATAN PALIATIF TERHADAP KUALITAS HIDUP PASIEN KANKER PAYUDARA
}

\author{
Irma Nur Amalia ${ }^{1}$, Mia Listia ${ }^{2}$ \\ Sekolah Tinggi Ilmu Kesehatan Dharma Husada Bandung ${ }^{1,2}$ \\ irma.nuramalia@yahoo.com ${ }^{1}$
}

\begin{abstract}
ABSTRAK
Penelitian ini bertujuan untuk mengidentifikasi pengaruh perawatan paliatif terhadap kualitas hidup pasien kanker payudara. Metode yang digunakan dalam penelitian ini adalah literature review. Hasil penelitian menunjukan bahwa perawatan paliatif berpengaruh terhadap pasien kanker payudara. Simpulan, perawatan paliatif yang komprehensif dari berbagai aspek kehidupan pasien sangat berperan dalam tercapainya kualitas hidup maksimal pada pasien kanker payudara smapai dengan upaya untuk memperisapkan kematian yang bermartabat.
\end{abstract}

Kata Kunci: Kanker Payudara, Kualitas Hidup, Perawatan Paliatif

\section{ABSTRACT}

This study aims to identify the effect of palliative care on breast cancer patients' quality of life. The method used in this study is a literature review. The results showed that palliative care affected breast cancer patients. In conclusion, comprehensive palliative care from various aspects of the patient's life plays a significant role in achieving the maximum quality of life in breast cancer patients and preparing for a dignified death.

Keywords: Breast Cancer, Quality of Life, Palliative Care

\section{PENDAHULUAN}

Data Globocan menyebutkan di tahun 2018 terdapat 18,1 juta kasus baru dengan angka kematian sebesar 9,6 juta kematian, dimana 1 dari 5 laki-laki dan 1 dari 6 perempuan di dunia mengalami kejadian kanker. Angka kejadian penyakit kanker di Indonesia (136.2/100.000 penduduk). Berdasarkan data Riskesdas, prevalensi tumor/kanker di Indonesia menunjukkan adanya peningkatan dari 1.4 per 1000 penduduk di tahun 2013 menjadi 1,79 per 1000 penduduk pada tahun 2018 .

Perawatan paliatif menjadi salah satu pilihan terbaru dalam tata laksana pengobatan kanker payudara.Perawatan paliatif ditujukan pada pasien dan keluarga dalam menghadapi isu-isu terkait dengan kondisi yang mengancam jiwa melalui pencegahan dengan identifikasi dini, pengkajian benar, dan penanganan nyeri serta gejala psikologis, spiritual, dan fisik. Kebutuhan akan perawatan paliatif meningkat sejalan dengan tingginya populasi, penyakit kronis, dan penyakit tidak menular. Perawatan paliatif tidak hanya dilakukan di rumah sakit melainkan dapat juga dilakukan di komunitas (Irawan et al., 2017). Namun masih jarang terdapat perawatan paliatif di rumah sakit karena masih berfokus kepada kuratif. Sedangkan perubahan secara fisik, social dan spiritual tidak bisa diintervensi seluruhnya dengan kuratif. 
Perawatan paliatif pada pasien dengan kanker payudara memang tidak mempengaruhi keseluruhan aspek dari kualitas hidup secara langsung sesuai dengan penelitian Krug et al., (2016) bahwa Hal yang sangat menggangu pasien dari penyakitnya adalah gejala nyeri, kecemasan, dan kelelahan. Maka untuk meningkatkan kualitas hidup pasien perlu diturunkan rasa kecemasan dan depresi yang dialami pasien dengan cara pemberian intervensi perawatan paliatif dengan demikian beban perawat/ pengasuh keluarga akan bekurang pula. Kualitas hidup pasien ini berhubungan dengan tingkat isolasi sosial yang tinggi dan distres emosional, yang juga mengakibatkan rendahnya fungsi fisik dan adanya ketidakmampuan pasien, serta gejala-gejala fisik. Hal ini menguatkan bahwa dibutuhkan perawatan kesehatan dan sosial yang lebih tinggi dimana perawatan paliatif diharapkan bisa menjadi pilihan terbaik untuk memenuhi kebutuhan pasien kanker payudara.

Intervensi perawatan paliatif yang diberikan akan efektif meningkatkan kualitas hidup pasien jika perawatan dilakukan dengan tingkat pelayanan yang baik dan secara signifikan dapat meningkatkan kepuasan pasien terhadap perawatan paliatif, sejalan dengan penelitian yang dilakukan Aboshaiqah et al., (2016) yang menyatakan bahwa penting untuk semua anggota tim kesehatan harus mengetahui penyediaan layanan dan perawatan kesehatan yang diperlukan untuk pasien kanker agar meningkatkan kepuasan pasien dalam perawatan sehingga perawatan paliatif yang diberikan dapat efektif meninggkatkan kualitas hidup pasien.

\section{METODE PENELITIAN}

Metode penelitian yang digunakan adalah dengan systematic review, yaitu cara untuk mengidentifikasi, mengevaluasi dan menafsirkan penelitian tentang efektifitas perawatan palitif terhadap kualitas hidup pasien dengan kanker payudara yang tersedia dan relevan dengan melakukan penelusuran artikel publikasi Medline pada PubMed, EBSCO dan Sciensdirect serta penelusuran secara manual menggunakan Google Search dengan kata kunci yang dipilih"Paliative Care" and "Quality Of Life" dan "Paliative Care" And "Breast Cancer" And "Quaility Of Life" or perawatan paliatif, Kualitas Hidup pasien kanker payudara. Pada tahap awal pencarian artikel jurnal diperoleh 50 artikel dari 2013 sampai 2018. Kemudian diidentifikasi dan dilakukan analisa untuk mencari keterkaitan dengan topik yang akan diteliti. Dari jumlah tersebut hanya sekitar 12 artikel yang dianggap relevan. Penulis mengidentifikasi, menilai, memilih dan mensintesa semua bukti penelitian dan pendapat setiap penulis jurnal dalam penelitian yang mereka lakukan.

Pengkajian yang dilakukan diantaranya adalah analisa masing-masing jurnal dengan metode PICO yaitu (Population or Problem, Intervention, Comparison, Outcome). Langkah selanjutnya membuat resensi matriks yang terdiri dari kolom-kolom yang memuat data jurnal yang terdiri dari nama, judul, dan tanggal penelitian, metode penelitian serta hasil penelitian pada setiap literatur. Langkah terakhir adalah melakukan pembahasan jurnal dengan cara membuat ringkasan berbagai literature dalam berbentuk matriks, melakukan analisis dengan membahas kesamaam (Compare), ketidaksamaan (Contrast), memberikan pandangan (Criticize) terhadap sumber yang di bacadan membandingkan (Synthensiz). 
HASIL PENELITIAN

Tabel. 1

Summary Artikel

\begin{tabular}{|c|c|c|c|c|}
\hline No. & $\begin{array}{c}\text { Pengarang, } \\
\text { Judul, Jenis } \\
\text { Literatur }\end{array}$ & Tahun & Tujuan & Hasil temuan \\
\hline 1 & $\begin{array}{l}\text { Correlation } \\
\text { between patient } \\
\text { quality of life in } \\
\text { palliative care } \\
\text { and burden of } \\
\text { their family } \\
\text { caregivers: a } \\
\text { prospective } \\
\text { observational } \\
\text { cohort study } \\
\text { (Krug et al., } \\
\text { 2016) }\end{array}$ & 2016 & $\begin{array}{l}\text { Penelitian } \\
\text { dilakukan untuk } \\
\text { mengidentifikasi } \\
\text { korelasi antara } \\
\text { perubahan } \\
\text { kualitas hidup } \\
\text { pasien dan } \\
\text { mengubah beban } \\
\text { pengasuh } \\
\text { keluarga yang } \\
\text { perlu } \\
\text { pertimbangan } \\
\text { dalam } \\
\text { manajemen } \\
\text { pasien. Metode } \\
\text { dalam penelitian } \\
\text { adalah studi } \\
\text { kohort prospektif } \\
\text { observasional }\end{array}$ & $\begin{array}{l}\text { Penelitian dilakukan pada } 100 \\
\text { orang pasien terdiri dari } 63 \text { laki- } \\
\text { laki } 37 \text { perempuan pasien kanker } \\
\text { dengan pemberian paliaf dalam } \\
\text { perawatan primer kemudian } \\
\text { dievalusai kualitas hidupnya } \\
\text { menggunaan kuesioner (Quality of } \\
\text { Life Questionnaire Inti } 15 \\
\text { Perawatan Paliatif, QLQ-C15- } \\
\text { PAL). Responden dinilai perbulan } \\
\text { untuk selang waktu } 6 \text { bulan atau } \\
\text { sampai kematian pasien. Hasil } \\
\text { penelitian didapatkan Pasien } \\
\text { melaporkan kualitas hidup secara } \\
\text { keseluruhan meningkat menjelang } \\
\text { akhir hidup, meskipun melaporkan } \\
\text { bahwa fungsi fisik memburuk. } \\
\text { Gejala nyeri dan kelelahan yang } \\
\text { paling mengganggu pasien. Maka } \\
\text { dari penelitian tersebut dapat } \\
\text { disimpulkan bahwa untuk } \\
\text { meningkatkan kualitas hidup } \\
\text { pasien perlu diturunkan rasa } \\
\text { kecemasan dan depresi yang } \\
\text { dialami pasien dengan cara } \\
\text { pemberian intervensi perawatan } \\
\text { paliatif dengan demikian beban } \\
\text { perawat/ pengasuh keluarga akan } \\
\text { bekurang. }\end{array}$ \\
\hline 2 & $\begin{array}{l}\text { Patients, } \\
\text { understanding of } \\
\text { treatment goals } \\
\text { and disease } \\
\text { course and their } \\
\text { relationship with } \\
\text { optimism, hope, } \\
\text { and quality of } \\
\text { life: a } \\
\text { preliminary among } \\
\text { study breast } \\
\text { advanced bancer } \\
\text { outpatients } \\
\text { before receiving } \\
\text { palliative } \\
\text { treatment (Soylu, } \\
\text { 2016) }\end{array}$ & 2016 & $\begin{array}{l}\text { Penelitian Cem } \\
\text { Soylul et al } \\
(2016) \\
\text { mempunyai dua } \\
\text { tujuan, salah } \\
\text { satunya adalah } \\
\text { untuk } \\
\text { mengevaluasi } \\
\text { hubungan } \\
\text { mereka dengan } \\
\text { optimisme, dan } \\
\text { harapan, hidup } \\
\text { kualitas pasien } \\
\text { pada kanker payudara } \\
\text { kankadium lanjut }\end{array}$ & $\begin{array}{l}\text { Penelitian dilakukan di klinik rawat } \\
\text { jalan Departemen Onkologi Medis, } \\
\text { Sekolah dan Rumah Sakit } \\
\text { Universitas Hacettepe kepada } 55 \\
\text { pasien. Metode dalam penelitian } \\
\text { tersebut adalah Perbandingan } \\
\text { statistik data kategorikal dilakukan } \\
\text { menggunakan uji chi-square, dan } \\
\text { uji Mann - whitney U Tes } \\
\text { dilakukan untuk membandingkan } \\
\text { setiap subskala dari kualitas hidup, } \\
\text { harapan, dan optimisme between } \\
\text { dua kelompok. Hasil penelitian } \\
\text { menunjukkan bahwa } 58,2 \% \text { dari } \\
\text { pasien memiliki persepsi yang } \\
\text { tidak akurat niat pengobatan, } \\
\text { percaya tujuan pengobatan adalah } \\
\text { penyembuhan, sedangkan hanya } \\
38,2 \% \text { dari pasien memiliki } \\
\text { harapan yang realistis bahwa } \\
\text { penyakit mereka mungkin tetap }\end{array}$ \\
\hline
\end{tabular}




\begin{tabular}{|c|c|c|c|c|}
\hline & & & & $\begin{array}{l}\text { stabil atau dapat berkembang lebih } \\
\text { dari satu tahun. Kesimpulan dari } \\
\text { penelitian tersebut adalah sebagian } \\
\text { besar pasien yang didiagnosis } \\
\text { dengan kanker payudara lanjut } \\
\text { percaya bahwa perlakuan mereka } \\
\text { adalah kuratif dan mereka akan } \\
\text { memperbaiki dalam waktu satu } \\
\text { tahun. }\end{array}$ \\
\hline 3 & $\begin{array}{l}\text { Spirituality- } \\
\text { Focused } \\
\text { Palliative Care } \\
\text { to Improve } \\
\text { Indonesian } \\
\text { Breast Cancer } \\
\text { Patient Comfort } \\
\text { (Nuraini et al., } \\
\text { 2018) }\end{array}$ & 2018 & $\begin{array}{l}\text { Penelitian } \\
\text { bertujuan } \\
\text { Mengembangkan } \\
\text { suatu jalur model } \\
\text { hubungan antara } \\
\text { variabel asuhan } \\
\text { keperawatan } \\
\text { (informasi, } \\
\text { dukungan } \\
\text { emosional, } \\
\text { dukungan teknis, } \\
\text { dan perawatan } \\
\text { paliatif),koping } \\
\text { pasien, dukungan } \\
\text { keluarga, } \\
\text { spiritualitas } \\
\text { pasien, dan } \\
\text { kenyamanan } \\
\text { pasien yang } \\
\text { diungkapkan } \\
\text { melalui mediator } \\
\text { fisik dan } \\
\text { emosional }\end{array}$ & $\begin{array}{l}\text { Menggunakan metode } r \text { cross- } \\
\text { sectional. Melibatkan } 308 \text { pasien } \\
\text { kanker payudara stadium } 2 \text { atau } \\
\text { lebih dan sistem } r \text { saraf } \\
\text { pusatmetastasisdari } 3 \text { rumah sakit } \\
\text { rujukan di Jakarta. Hasil penelitian } \\
\text { tersebut menunjukkan sumber- } \\
\text { sumber individu (mengatasi, } \\
\text { spiritualitas, lan } \\
\text { keluargadukungan) dan layanan } \\
\text { keperawatan memperoleh nilai } \\
\text { tinggi. Hubungan positif yang } \\
\text { signifikan(P = 0,05; r }=0,098) \\
\text { antara spiritualitas dan pasien } \\
\text { ketidaknyamanan melalui mediator } \\
\text { emosional yang rendah. Hasilnya } \\
\text { menunjukkan bahwa responden } \\
\text { yang lebih dekatTuhan lebih } \\
\text { mungkin memiliki emosi yang } \\
\text { lebih baik. Dengan demikian Efek } \\
\text { positif dari perawatan paliatif } \\
\text { dilihat dari peningkatan } \\
\text { kenyamanan pasien. }\end{array}$ \\
\hline 4 & $\begin{array}{l}\text { Communication } \\
\text { in palliative } \\
\text { care: talking } \\
\text { about the end of } \\
\text { life, before the } \\
\text { end of life Lisa } \\
\text { Jane Brighton, } \\
\text { Katherine } \\
\text { Bristowe \& } \\
\text { (Brighton } \\
\text { Bristowe, 2016) }\end{array}$ & 2106 & $\begin{array}{l}\text { Penelitian } \\
\text { membahas } \\
\text { mengenai } \\
\text { komunikasi } \\
\text { dalam perawatan } \\
\text { paliatif dan } \\
\text { mempersiapakan } \\
\text { pasien menjelang } \\
\text { akhir hayat }\end{array}$ & 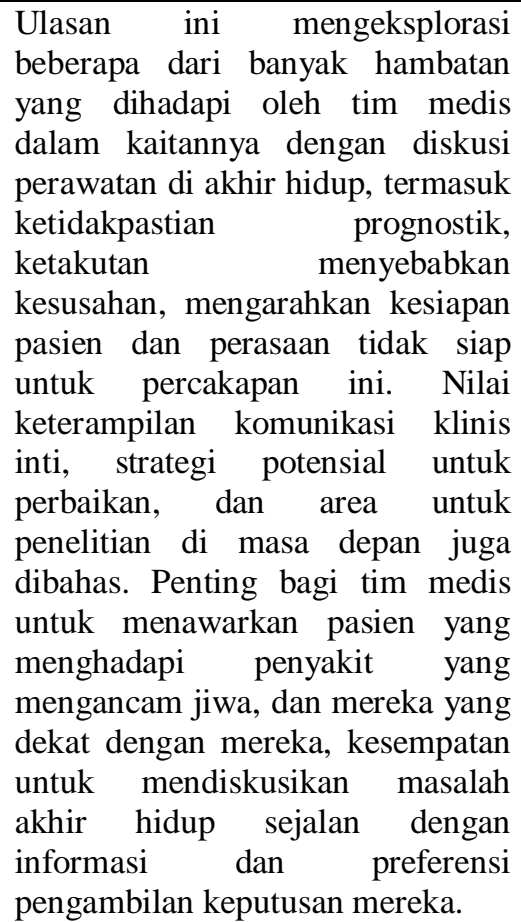 \\
\hline
\end{tabular}




\begin{tabular}{|c|c|c|c|c|}
\hline 5 & $\begin{array}{l}\text { Hubungan } \\
\text { Dukungan } \\
\text { Spiritual Dan } \\
\text { Dukungan Sosial } \\
\text { Dengan Kualitas } \\
\text { Hidup Pasien } \\
\text { Kanker Payudara } \\
\text { Di RSUD Prof. } \\
\text { Dr. Margono } \\
\text { Soekarjo } \\
\text { Purwokerto \& } \\
\text { (Endiyono \&erdiana, 2016) }\end{array}$ & 2016 & $\begin{array}{lr}\text { Artikel } & \text { ini } \\
\text { membahas } & \\
\text { tentang } & \\
\text { hubungan } & \text { tingkat } \\
\text { dukungan } & \\
\text { spiritual } & \text { dan } \\
\text { dukungan } & \text { sosial } \\
\text { dengan } & \text { kualitas } \\
\text { hidup rad } & \text { pada } \\
\text { pasien } & \text { dengan } \\
\text { kanker payudara. }\end{array}$ & $\begin{array}{l}\text { Menggunakan metode } \\
\text { deskripsi kenelitian } \\
\text { pendekatan cross sectional dan } \\
\text { teknik incidental sampling, jumlah } \\
\text { responden sebanyak } \\
\text { responden.Berdasarkan } \\
\text { analisis menggunakan hasil } \\
\text { Squaremenunjukan bahwa adanya } \\
\text { hubungan yang signifikan antara } \\
\text { dukungan spiritual dengan kualitas } \\
\text { hidup pasien } \\
\text { payudarapvalue<alpha(0.012< } \\
\text { 0,05). Dengan kata lain Ho } \\
\text { ditolak, ini menunjukan dukungan } \\
\text { sosial yang diberikan terhadap } \\
\text { pasien kanker payudara } \\
\text { berpengaruh terhadap kualitas } \\
\text { hidup pasien kanker payudara di } \\
\text { RSUD Prof. Dr. Margono Soekarjo } \\
\text { Purwokerto. }\end{array}$ \\
\hline 6 & $\begin{array}{l}\text { Psychosocial } \\
\text { Service Model In } \\
\text { Palliative Care } \\
\text { For Breast } \\
\text { Cancer Patients } \\
\text { (Putri \& \& } \\
\text { Suryanto, 2019) }\end{array}$ & 2019 & $\begin{array}{l}\text { Layanan } \\
\text { psikososial } \\
\text { adalah perawatan } \\
\text { secara psikologis } \\
\text { dan } \\
\text { terhadap posial } \\
\text { dengan penyakit } \\
\text { kronis di yang } \\
\text { akan } \\
\text { berpengaruh } \\
\text { pada kondisi } \\
\text { fisik, sosial, } \\
\text { kognitif, emosi } \\
\text { serta masalah } \\
\text { psikologis } \\
\text { lainnya yang } \\
\text { dialami } \\
\text { pasien oleh } \\
\text { keluarga } \\
\text { sepanjang dan } \\
\text { penyakitnya }\end{array}$ & $\begin{array}{lr}\text { Tujuan penelitian ini } & \text { adalah } \\
\text { mendeskripsikan model layanan } \\
\text { psikososial dalam perawatan } \\
\text { paliatif pada pasien kanker } \\
\text { payudara. Penelitian } r \text { ini } \\
\text { menggunakan pendekatan kualitatif } \\
\text { dengan desain studi kasus. } \\
\text { Berdasarkan hasil penelitian, dapat } \\
\text { disimpulkan bahwa model-model } \\
\text { layanan psikososial yang diberikan } \\
\text { oleh tim paliatif yaitu pemberian } \\
\text { dukungan sosial dalam program } \\
\text { Kelompok Dukungan Paliatif, } \\
\text { intervensi psikologis, layanan } \\
\text { home visit dan home care, serta } \\
\text { penyuluhan komunitas.. }\end{array}$ \\
\hline 7 & $\begin{array}{l}\text { Relationship } \\
\text { between Modern } \\
\text { and } \\
\text { Complementary } \\
\text { Therapies on the } \\
\text { Life Quality of } \\
\text { Breast Cancer } \\
\text { Patients } \\
\text { Undergoing } \\
\text { Chemotherapy } \\
\text { (Irawan et al., } \\
\text { 2017) }\end{array}$ & 2017 & $\begin{array}{l}\text { Bertujuan untuk } \\
\text { mengidentifikasi } \\
\text { hubungan } \\
\text { penggunaan } \\
\text { terapi modern } \\
\text { dan } \\
\text { komplementer } \\
\text { dengan kualitas } \\
\text { hidup pasien } \\
\text { dengan kanker } \\
\text { payudara yang } \\
\text { menjalani } \\
\text { kemoterapi }\end{array}$ & $\begin{array}{l}\text { Dengan jumlah sampel } 178 \text { orang } \\
\text { yang direkrut menggunakan } \\
\text { accidentalsampling selama tiga } \\
\text { bulan. Didapatkan } \\
\text { karakteristik stadium memiliki } \\
\text { hubunganpositif yang signifikan } \\
\text { dengan kualitashidup pasien } \\
\text { dengan p-value }=0,002 \text {, dukungan } \\
\text { keluarga memiliki hubungan } \\
\text { positif yang signifikan dengan } \\
\text { kualitas hidup denganp-value }= \\
0,001 \text {,terdapat hubungan positif } \\
\text { yang signifikan antara terapi } \\
\text { modern dan komplementer } \\
\text { terhadap kualitas hidup } \\
\text { pasienkanker payudara p-value }= \\
0,00 \text { dan } \rho \text { (rho)= }+0,2 \text {. Peneliti }\end{array}$ \\
\hline
\end{tabular}




\begin{tabular}{|c|c|c|c|c|}
\hline & & & & $\begin{array}{l}\text { menyimpulkan bahwa terapi } \\
\text { modern yang dibarengi herbal } \\
\text { ataupun dengan } \\
\text { komplementer terapi } \\
\text { memiliki hubunganpositif yang } \\
\text { signifikan terhadap kualitas hidup } \\
\text { pada pasienkanker payudara yang } \\
\text { menjalani kemoterapi. }\end{array}$ \\
\hline 8 & 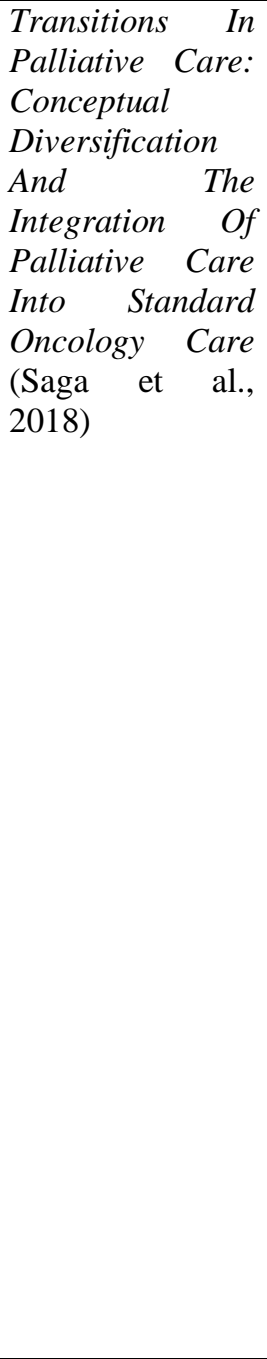 & 2018 & $\begin{array}{l}\text { Artiket tersebut } \\
\text { berisi tentang } \\
\text { tinjaun konsep } \\
\text { dan } \\
\text { perkembangan } \\
\text { sejarah } \\
\text { perawatan } \\
\text { paliatif, serta } \\
\text { menggambarkan } \\
\text { integrasi } \\
\text { perawatan } \\
\text { paliatif } \\
\text { perawatan } \\
\text { onkologi standar } \\
\text { yang dapat } \\
\text { meningkatkan } \\
\text { kualitas hidup } \\
\text { pasien dengan } \\
\text { kanker }\end{array}$ & $\begin{array}{l}\text { Penulis membahas perawatan } \\
\text { paliatif tahap awal telah dilaporkan } \\
\text { dapat meningkatkan kualitas hidup } \\
\text { pasien, dapat memperbaiki depresi, } \\
\text { mengurangi beban pada keluarga, } \\
\text { dan meningkatkan prognosis } \\
\text { kelangsungan hidup untuk } \\
\text { beberapa kanker stadium lanjut. } \\
\text { Saat ini, upaya untuk } \\
\text { mengintegrasikan perawatan } \\
\text { paliatif ke dalam rejimen } \\
\text { perawatan onkologi standar dengan } \\
\text { menyediakan perawatan paliatif } \\
\text { khusus dan pengobatan kanker } \\
\text { sebagai satu unit diperkirakan akan } \\
\text { memasuki praktik yang lebih luas. } \\
\text { Pendekatan perawatan semacam ini } \\
\text { berbeda dari perawatan paliatif } \\
\text { konvensional, yang dimulai sekitar } \\
\text { waktu ketika akhir pengobatan } \\
\text { kanker konvensional, dan terdiri } \\
\text { dari penerapan perawatan paliatif } \\
\text { khusus dari tahap di mana } \\
\text { perawatan kanker diberikan untuk } \\
\text { mengatasi berbagai masalah. } \\
\text { Banyak pasien kanker payudara } \\
\text { mengalami masalah berat seperti } \\
\text { efek estetik, seksualitas dan efek } \\
\text { psiko-sosial yang terkait dengan } \\
\text { kanker payudara itu sendiri dan } \\
\text { pengobatan. Dan itu efek QOL } \\
\text { untuk waktu yang lama tidak hanya } \\
\text { selama terapi tetapi juga telah } \\
\text { melakukan terapi atau kekambuhan }\end{array}$ \\
\hline 9 & $\begin{array}{l}\text { Pengaruh } \\
\text { Pemberian } \\
\text { Booklet } \\
\text { Kemoterapi } \\
\text { Terhadap } \\
\text { Kemampuan } \\
\text { Perawatan Diri } \\
\text { Penderita Kanker } \\
\text { Payudara Pasca } \\
\text { Kemoterapi Di } \\
\text { Ruang Bedah } \\
\text { Rumah Sakit } \\
\text { Abdul Moeloek } \\
\text { (RSAM) Bandar } \\
\text { Lampung (Anita } \\
\text { \& Sukamti, }\end{array}$ & 2016 & $\begin{array}{l}\text { Tujuan penelitian } \\
\text { untuk } \\
\text { mengetahui } \\
\text { Pengaruh } \\
\text { pemberian } \\
\text { Booklet } \\
\text { Kemoterapi } \\
\text { terhadap } \\
\text { Kemampuan } \\
\text { Perawatan Diri } \\
\text { Penderita Kanker } \\
\text { Payudara Pasca } \\
\text { Kemoterapi di } \\
\text { Ruang Bedah } \\
\text { Rumah Sakit } \\
\text { Abdul Moeloek }\end{array}$ & $\begin{array}{l}\text { Penelitian dilakukan mulai tanggal } \\
1-30 \text { Januari } 2016 \text {, desain quasi } \\
\text { eksperimen dengan one group, pre } \\
\text { test dan post test. Populasi } 65 \text { ibu } \\
\text { dengan kanker payudara pasca } \\
\text { kemoterapi, sampel sejumlah } 56 \\
\text { responden. Hasil penelitian } \\
\text { diperoleh nilai rata-rata perilaku } \\
\text { perawatan diri penderita kanker } \\
\text { payudara pasca kemoterapi } \\
\text { sebelum pemberian booklet adalah } \\
4,70 \text { dengan standar deviasi } 1,249 . \\
\text { Nilai rata-rata nilai perilaku } \\
\text { perawatan diri penderita kanker } \\
\text { payudara pasca kemoterapi setelah } \\
\text { pemberian booklet adalah } 7,82\end{array}$ \\
\hline
\end{tabular}




\begin{tabular}{|c|c|c|c|c|}
\hline & 2016) & & $\begin{array}{l}\text { (RSAM) Bandar } \\
\text { Lampung } 2016\end{array}$ & $\begin{array}{l}\text { dengan standar deviasi } 1,478 \text {. Hasil } \\
\text { uji statistik didapatkan nilai p= } \\
0,000 \text {, berarti pada alpha } 5 \% \\
\text { dismpulkan bahwa ada pengaruh } \\
\text { yang signifikan antara perilaku } \\
\text { perawatan diri penderita kanker } \\
\text { payudara pasca }\end{array}$ \\
\hline 10 & $\begin{array}{l}\text { Quality of life } \\
\text { and satisfaction } \\
\text { with care among } \\
\text { palliative cancer } \\
\text { patients in Saudi } \\
\text { Arabia } \\
\text { (Aboshaiqah et } \\
\text { al., 2016) }\end{array}$ & 2016 & $\begin{array}{l}\text { Penelitian } \\
\text { tersebut } \\
\text { bertujuan untuk } \\
\text { mengetahui } \\
\text { hubungan antara } \\
\text { kualitas hidup } \\
\text { dan kepuasan } \\
\text { dengan } \\
\text { perawatan pada } \\
\text { pasien kanker } \\
\text { dalam perawatan } \\
\text { paliatif. }\end{array}$ & 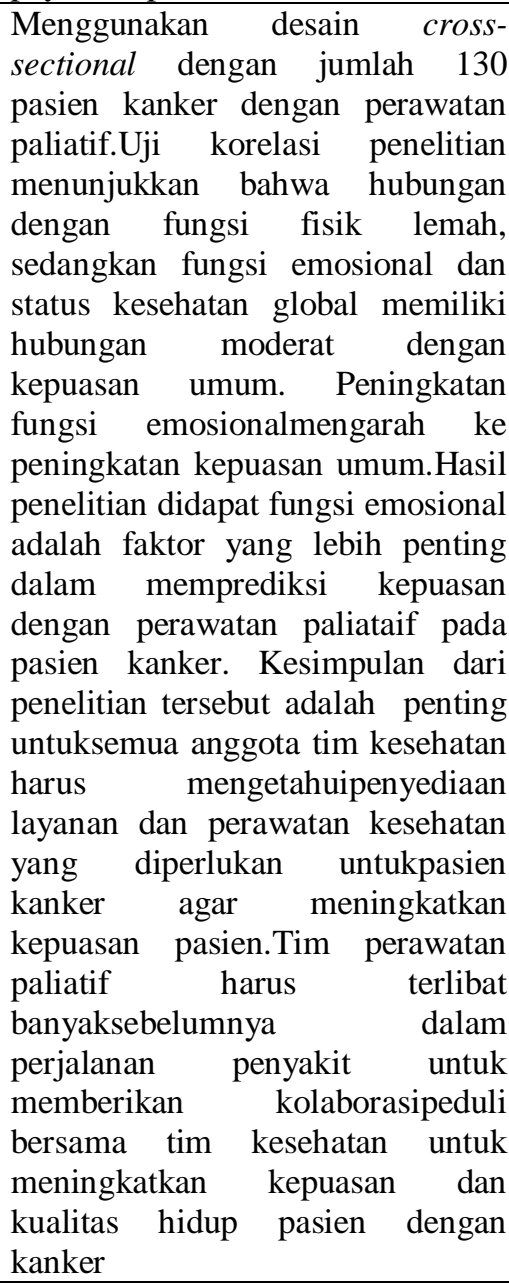 \\
\hline 11 & $\begin{array}{l}\text { Self-efficacy for } \\
\text { Coping } \\
\text { Moderates the } \\
\text { Effects of } \\
\text { Distress on } \\
\text { Quality of Life in } \\
\text { Palliative } \\
\text { Cancer Care } \\
\text { (Chirico et al., } \\
\text { 2017) }\end{array}$ & 2017 & & $\begin{array}{l}\text { Penelitian ini merupakan perluasan } \\
\text { dari peran efikasi diri untuk } \\
\text { mengatasi perawatan paliatif. } \\
\text { Dengan menggunakan model } \\
\text { stress-coping, tujuan utama dari } \\
\text { penelitian ini adalah untuk } \\
\text { mengevaluasi model proses, } \\
\text { dimana self-efficacy untuk } \\
\text { mengatasi kanker merupakan } \\
\text { pemoderasi antara stres dan } \\
\text { kualitas hidup pada sampel pasien } \\
\text { kanker payudara dalam perawatan } \\
\text { paliatif }\end{array}$ \\
\hline 12 & $\begin{array}{l}\text { Gambaran } \\
\text { Kualitas Hidup } \\
\text { Pasien Kanker } \\
\text { Stadium Lanjut } \\
\text { Yang Menjalani } \\
\text { Radioterapi }\end{array}$ & 2017 & $\begin{array}{l}\text { Energi ionisasi } \\
\text { radioterapi } \\
\text { mengatasi gejala } \\
\text { dengan tindakan } \\
\text { langsung dan } \\
\text { tidak langsung }\end{array}$ & $\begin{array}{l}\text { Tujuan penelitian ini adalah untuk } \\
\text { mendeskripsikan kualitas hidup } \\
\text { penderita kanker stadium lanjut } \\
\text { lead radioterapi paliatif di RSUD } \\
\text { Arifin Achmad Provinsi Riau. } \\
\text { Metode penelitian yang digunakan }\end{array}$ \\
\hline
\end{tabular}




\begin{tabular}{|c|c|}
\hline $\begin{array}{l}\text { Paliatif } \\
\text { RSUD Di } \\
\text { Achmad Provinsin } \\
\text { Riau (Harfendi } \\
\text { et al., 2017) }\end{array}$ & $\begin{array}{l}\text { adalah studi deskriptif dengan } \\
\text { menggunakan rekam medik pasien } \\
\text { yang menjalani radioterapi paliatif } \\
\text { dan wawancara menggunakan } \\
\text { kuesioner WHOQOL-BREF. Kami } \\
\text { memperoleh } 24 \text { sampel dengan } \\
\text { karakteristik: kelompok usia } \\
\text { terbesar } 36-45 \text { tahun (33,3\%), } \\
\text { sebagian besar perempuan } \\
(79,9 \%) \text { Diagnosis keganasan } \\
\text { primer yang paling umum adalah } \\
\text { kanker payudara (75,0\%) dan } \\
\text { sebagian besar iradiasi lokal } \\
\text { ditemukan dalam penelitian ini } \\
(79,2 \%) \text { Rerata dimensi kualitas } \\
\text { hidup tertinggi pada dimensi } \\
\text { lingkungan (70,6\%) dan terendah } \\
\text { pada dimensi fisik (47,25\%). }\end{array}$ \\
\hline
\end{tabular}

Berdasarkan tabel 1 menunjukkan bahwa artikel yang di review terdiri dari 12 artikel mulai dari tahun 2016 sampai dengan tahun 2019. Dari beberapa penelitian tersebut didapatkan bahwa terapi yang biasa digunakan untuk meningkatkan kenyamanan dan kualitas hidup pasien kanker adalah dengan cara memberikan intervensi perawatan paliatif, kuratif, dukungan spiritual. Selain itu, di Indonesia terdapat beberapa prinsip pengobatan kanker diantaranya melalui pembedahan, radiasi, kemoterapi, hormonal terapi, dan imunoterapi. Pengobatan yang tidak dilakukan dengan benar mengakibatkan angka harapan hidup yang lebih pendek. Pasien dengan kondisi tersebut membutuhkan pendekatan terintegrasi agar pasien memiliki kualitas hidup yang baik dan pada akhirnya akan meninggal dengan damai dan bermartabat. Penatalaksanaan kanker sangat berkembang pesat akan tetapi angka harapan hidup pasien masih belum seperti yang diharapkan.

Kematian akibat kanker di seluruh dunia, kanker payudara menjadi urutan pertama penyebab kematian. Umumnya kanker payudara terjadi pada wanita pasca menoupause walaupun pada usia muda banyak ditemukan yaitu usia kurang dari 25 tahun dan pada pria hanya sedikit kasus yang ditemukan. Kanker yang ditemukan pada stadium dini, akan mendapat pengobatan yang cepat dan tepat, serta memberikan kesembuhan dan harapan hidup lebih lama kepada pasien. Perawatan paliatif menjadi salah satu pilihan terbaru dalam tata laksana pengobatan kanker payudara. Kebutuhan akan perawatan paliatif meningkat sejalan dengan tingginya populasi, penyakit kronis, dan penyakit tidak menular. Perawatan paliatif tidak hanya dilakukan di rumah sakit melainkan dapat juga dilakukan di komunitas.

\section{PEMBAHASAN}

Hasil beberapa artikel penelitian yang dianalisis menekankan bahwa kualitas hidup pasien dengan kanker payudara sangat penting untuk diintergrasikan dalam intervensi perawatan. Kualitas hidup mencakup evaluasi subyektif tentang dampak dari penyakit dan pengobatannya dalam hubungannya dengan tujuan, nilai dan harapan seseorang, sedangkan status fungsional memberikan suatu penilaian obyektif dari kemampuan fisik dan emosional penderita kanker mendefinisikan kualitas hidup sebagai kepuasan dalam berbagai aspek kehidupan (Nuraini et al., 2018). World Health Organization (WHO) menyatakan quality of life as individual's perception of their 
position in life in the context of the culture and value system in which they live and in relation to their goals, espextation, standart and concerns. Artinya, kualitas hidup merupakan persepsi dari individu dalam kehidupan dalam konteks budaya dan sistem nilai dimana mereka hidup dan dalam kaitannya dengan nilai-nilai, standart dan kekhawatiran dalam hidup.

Aspek-aspek dalam kualitas hidup termasuk komponen fisik, emosional dan fungsional. Status fungsional mengacu pada kemampuan melakukan aktifitas yang berhubungan dengan kebutuhan dan ambisi atau peran sosial yang diinginkan oleh pasien, pada tahap yang paling dasar mengacu pada kemampuan melakukan aktifitas sehari-hari. Hal ini juga terkait dengan cara seseorang menerima keadaan fisiknya. Beberapa penelitian artikel juga menunjukan bahwa pasien dengan kanker payudara mengalami masalah berat seperti efek estetik, seksualitas dan efek psiko-sosial yang terkait dengan kanker payudara itu sendiri dan pengobatan. Untuk meningkatkan kualitas hidup pasien dengan kanker payudara diperlukan pendekatan secara menyeluruh baik dukungan medis, keluarga, sosial dan dari pasien sendiri. Sehingga diperlukan komunikasi serta kerjasama yang baik dari semua pihak yang terlibat guna meningkatkan kualitas hidup pasien kanker payudara dalam perawatan paliatif (Brighton \& Bristowe, 2016).

Mayoritas pasien kanker payudara mengalami penurunan kualitas hidup drastis dalam beberapa minggu terakhir kehidupan. Paradigma baru perawatan palitif untuk pasien kanker payudara menghasilkan model pengobatan baru di mana efikasi diri tampaknya memegang peran penting (Chirico et al., 2017). Penelitian ini merupakan perluasan dari peran efikasi diri dalam perawatan paliatif. Menggunakan model stresscoping, penelitian ini bertujuan adalah untuk mengevaluasi model proses, dimana efikasi diri kan mempengaruhi tingkat stres dan kualitas hidup. Tujuan sekundernya adalah untuk memvalidasi skala efikasi diri mengatasi domain tertentu, dan didapatkan hasil dari 109 pasien yang terlibat dalam penelitian ini bahwa 58 yang memiliki kualitas hidup yang lebih baik dengan indeks komposit CBI-B IT berkorelasi positif dengan kualitas hidup secara keseluruhan, baik fungsi fisik, fungsi peran, emosional dan kognitif yang diukur dengan kuesioner QLQ-C30 ( $\mathrm{r}=356, \mathrm{p}=0.007 ; \mathrm{r}=0.270, \mathrm{p}=$ $0.040 ; \mathrm{r}=344, \mathrm{p}=0,008 ; \mathrm{r}=0,300, \mathrm{p}=0,023 ; \mathrm{r}=0,379, \mathrm{p}=0,004)$. Sedangkan skor koping efikasi diri yang lebih tinggi juga dikaitkan dengan kemampuan yang lebih besar untuk melawan penyakit pada pasien kanker payudara.

Tujuan dari peningkatan efikasi diri dalam perawatan paliatif ini juga adalah untuk meningkatkan optimisme pasien dalam menjalani perawatan sehingga diharapkan akan mempengaruhi tingkat kualitias hidup. Seiring dengan penelitian terhadap 55 pasien, diperoleh hasil bahwa 58,2\% dari pasien memiliki persepsi yang tidak akurat niat pengobatan, percaya tujuan pengobatan adalah penyembuhan, sedangkan hanya $38,2 \%$ dari pasien memiliki harapan yang realistis bahwa penyakit mereka mungkin tetap stabil tau tidak mengalami perburukan. Kesimpulan dari penelitian tersebut adalah sebagian besar pasien yang didiagnosis dengan kanker payudara stadium lanjut percaya bahwa kondisi kesehatan mereka akan mengalami perbaikan dalam waktu satu tahun (Soylu et al., 2016).

Dari aspek psikososial dalam perawatan palitif yang dilakukan pada pasien kanker payudara untuk meningkatakan kualitas hidup akan berpengaruh pada kondisi fisik, sosial, kognitif, emosi serta masalah psikologis lainnya yang dialami oleh pasien dan dan keluarga sepanjang penyakitnya. Tujuan penelitian ini adalah mendeskripsikan model layanan psikososial dalam perawatan paliatif pada pasien kanker payudara. 
Sejalan dengan hasil penelitian Putri \& Suryanto (2020) yang menyatakan bahwa model layanan psikososial yang diberikan oleh tim paliatif yaitu pemberian dukungan sosial dalam program kelompok dukungan paliatif, intervensi psikologis, layanan home visit dan home care, serta penyuluhan komunitas. Tim paliatif dapat mengembangkan keterampilan dalam memberikan intervensi kepada pasien serta diharapkan bagi pemberi layanan kesehatan terutama rumah sakit untuk mengembangkan secara optimal.

Faktor lainnya yang ikut berpengaruh dalam peningkatan kualitas hidup pasien yang terkait dengan pemberian perawatan paliatif yang komprehensif pada pasien kanker payudara adalah aspek pengobatan pada pasien. Menurut Wahyuningsih (2020) bahwa peran keluarga dalam meningkatkan kepatuhan pengobatan pasien sangat berpengaruh. Pengetahuan dan kemampuan keluarga dalam perawatan anggota keluarga dengan kanker payudara dan dukungan terhadap kontrol minum obat pada 5 keluarga Kelurahan Bandarharjo. Pengetahuan yang diberikan meliputi permasalahan pasien kanker, terapi kompelementer yaitu latihan progressive muscle relaxation, pembuatan jus buah bit dan pengisian monitoring obat. Topik terapi komplementer masing-masing untuk peserta, sehingga peserta diberikan edukasi dan sosialisasi terkait. Terapi lain yang diketahui dapat meingkatkan kualitas hidup pada pasien kanker salah satunya adalah radioterapi paliatif berupa pemberian energi ionisasi yang digunakan berupa foton dan elektron disesuaikan dengan kedalaman lokasi tumor. Penelitian ini diikuti oleh 24 pasien kanker payudara selam rentang waktu 2009-2015 dengan karakteristik pasien yang menjalani radioterapi paliatif terhadap kanker payudara stadium lanjut. Hasil penelitian menunjukan bahwa dimensi kualitas hidup pasien yang paling tinggi adalah dimensi lingkungan dan dimensi kualitas hidup yang paling rendah adalah dimensi fisik (Harfendi et al., 2017).

Dari beberapa penelitian terkait aspek yang mempengaruhi kualitas hidup pasien kanker payudara yang menjalani perawatan paliatif juga pada akhirnya harus dilakukan evaluasi terhadap tingkat kepuasan pasien sehingga peningkatan kualitas hidup dapat tercapai dengan baik. Penelitian serupa dilakukan oleh Aboshaiqah et al., (2016) yang bertujuan untuk mengetahui hubungan antara kualitas hidup dan kepuasan perawatan paliatif pada pasien kanker sebanyak 130 pasien. Semua peserta yang memenuhi syarat menjawab kuesioner yang mencakup data demografis dan kuesioner (EORTC QLQC15-PAL) dan (EORTC IN-PATSAT32) yang telah divalidasi. Diperoleh hasil partisipan sebagian besar berjenis kelamin perempuan (79\%) dan menikah (71\%), dan lebih dari separuh menderita kanker payudara (53\%). Hasil uji korelasi menunjukkan bahwa hubungan dengan fungsi fisik adalah lemah, sedangkan fungsi emosional dan status kesehatan global memiliki hubungan sedang dengan kepuasan umum ( $\mathrm{r}^{1} / 40.21, \mathrm{p}$, $0.01 ; \mathrm{r}^{1 / 40.32}, \mathrm{p}, 0.001 ; \mathrm{r}^{1} / 40.26, \mathrm{p}, 0.01$,). Hasil menunjukkan bahwa fungsi emosional adalah faktor yang lebih penting dalam memprediksi kepuasan perawatan di antara pasien kanker paliatif. Peningkatan fungsi emosional menyebabkan peningkatan kepuasan umum. Fungsi emosional pasien kanker paliatif lebih erat kaitannya dengan kepuasan secara keseluruhan terhadap perawatan daripada fungsi fisik atau status kesehatan global. Semua anggota tim perawatan paliatif dengan demikian diharuskan untuk memberikan dukungan psikososial yang memadai. Direkomendasikan bahwa pendekatan interdisipliner dan kolaboratif diintegrasikan dalam perawatan paliatif pasien kanker. 


\section{SIMPULAN}

Perawatan paliatif yang komprehensif dari berbagai aspek kehidupan pasien sangat berperan dalam tercapainya kualitas hidup maksimal pada pasien kanker payudara smapai dengan upaya untuk memperisapkan kematian yang bermartabat.

\section{SARAN}

Aspek perawatan diri dan efikasi diri harus ditunjang dengan dukungan keluarga dalam pengobatan. Begitu juga dukungan psikososial yang sangat berpengaruh dalam peningkatan kualitas hidup pasien terutama dalam aspek peningkatan fungsi emosi pasien penderita kanker payudara.

\section{DAFTAR PUSTAKA}

Aboshaiqah, A., Ph, D., \& Al-saedi, T. S. B. (2016). Quality of Life and Satisfaction with Care among Palliative Cancer Patients in Saudi Arabia. Palliative and Supportive Care, 14(6), 621-627. https://doi.org/10.1017/S1478951516000432

Brighton, L. J., \& Bristowe, K. (2016). Communication in Palliative Care: Talking about the End of Life, Before the End of Life. Postgraduate Medical Journal, 92(2090) 466-470. https://doi.org/10.1136/postgradmedj-2015-133368

Chirico, A., Serpentini, S., Merluzzi, T., Mallia, L., Bianco, P. D. E. L., Martino, R., Trentin, L., Bucci, E., \& Laurentiis, M. D. E. (2017). Self-Efficacy for Coping Moderates the Effects of Distress on Quality of Life in Palliative Cancer Care. Anticancer Research, 37(4), 1609-1615. DOI: https://doi.org/10.21873/anticanres.11491

Endiyono, E., \& Herdiana, W. (2016). Hubungan Dukungan Spiritual dan Dukungan Sosial dengan Kualitas Hidup Pasien Kanker Payudara di Rsud Prof. Dr. Margono Soekarjo Purwokerto. MEDISAINS: Jurnal Ilmiah Ilmu-Ilmu Kesehatan, 14(2), $16-23$

Irawan, E., Rahayuwati, L., Yani, D. I. (2017). Hubungan Penggunaan Terapi Modern dan Komplementer terhadap Kualitas Hidup Pasien Kanker Payudara Relationship between Modern and Complementary Therapies on the Life Quality of Breast Cancer Patients Undergoing Chemotherapy. Journal Nursing Padjajaran5(4), 1928. DOI: $10.24198 / \mathrm{jkp} . v 5 \mathrm{n} 1.3$

Krug, K., Miksch, A., Peters-klimm, F., Engeser, P., \& Szecsenyi, J. (2016). Correlation between Patient Quality of Life in Palliative Care and Burden of Their Family Caregivers: A Prospective Observational Cohort Study. BMC Palliative Care, 18. https://doi.org/10.1186/s12904-016-0082-y

Nuraini, T., Andrijono, A., Irawaty, D., Umar, J., \& Gayatri, D. (2018). Spirituality Focused Palliative Care to Improve Indonesian Breast Cancer Patient Comfort. Indian Journal of Palliative Care, 24(2), 196-201. DOI: https://doi.org/10.4103/IJPC.IJPC

Putri, A. A. N., \& Suryanto, S. (2020). Model Layanan Psikososial (Psychosocial Care) dalam Perawatan Paliatif pada Pasien Kanker Payudara. Prosiding Seminar Nasional Milleneial 5.0 Fakultas Psikologi UMBY. https://ejurnal.mercubuanayogya.ac.id/index.php/ProsidingPsikologi/article/view/1361

Saga, Y., Enokido, M., Iwata, Y., \& Ogawa, A. (2018). Transitions in Palliative Care : Conceptual Diversification and the Integration of Palliative Care Into Standard Oncology Care. Chinese Clinical Oncology, 7(3). https://doi.org/10.21037/cco.2018.06.02 
Soylu, C., Babacan, T., Sever, A. R., \& Altundag, K.. (2016). Patients' Understanding of Treatment Goals and Disease Course and Their Relationship with Optimism, Hope, and Quality of Life : A Preliminary Study Among Advanced Breast Cancer Outpatients Before Receiving Palliative Treatment. Supportive Care in Cancer, 24(8), 3481-3488. DOI: https://doi.org/10.1007/s00520-016-3182-6

Wahyuningsih, S.I., Janitra, E.F., \& Lestari, P.A. (2020). Pendampingan Program Farkom (Farmakology and complementary therapy) untuk Pasien dan Keluarga Penderita Kanker. 3(2), 95-101. http://dx.doi.org/10.33474/jipemas.v3i2.4912 